\title{
COMPOUNDING OF DISCRIMINATIVE STIMULI FROM THE SAME AND DIFFERENT SENSORY MODALITIES ${ }^{1}$
}

\author{
Laurence Miller
}

\author{
WESTERN WASHINGTON STATE COLLEGE
}

\begin{abstract}
Rats' responding was maintained by fixed-interval schedules of reinforcement in the presence of a tone or two separate lights. The lights were either of low, moderate, or high intensity. Compounds of these single discriminative stimuli each maintained a greater frequency of response than did the single stimuli, and the compound composed of stimuli from different sensory modalities (light + tone) maintained a greater level of responding than did the compound composed of stimuli from the same sensory modality (light + light). Combining lights of different intensity had no differential effect on responding. However, in the second experiment, a compound composed of a light and a tone, each of greater intensity than the light and tone of another compound, initially maintained a higher frequency of response, demonstrating intensity effects during stimulus compounding when the increase in intensity occurs through the component stimuli. This intensity effect, however, was only transitory.
\end{abstract}

When responding is maintained in the presence of two separate conditioned (CS) or discriminative $\left(\mathrm{S}^{\mathrm{D}}\right)$ stimuli, a higher magnitude or frequency of response may occur when the stimuli are combined (Hull, 1940; Wolf, 1963). Typically, the compound is composed of stimuli from different sensory modalities, or intermodal stimuli. These have ranged from compounds of odorous stimuli and electric shock (Kimble, 1961, p. 87), visual and tactual stimuli (Hull, 1940), to the most commonly used combination of visual and auditory stimuli (e.g., Wolf, 1963; Weiss, 1964; Miller and Price, 1971). Only rarely have the stimuli come from the same sense modality, or intra-modal stimuli, but the results are consistent with the intermodal results. Grings and O'Donnell (1956) compounded CSs of differently colored glass discs and Wolf (1963) compounded different combinations of lights. In both instances the compound maintained a greater level of responding than did either single stimulus.

Although inter- and intra-modal compounds have been examined, subjects have always been exposed to only one of the compound conditions, so that any difference in responding produced by the two sets of compounds could well be the result of individual differences in responding. In the present study, differences in level of responding maintained by each compound were examined by exposing each sub- ject to both kinds of compounds, consisting of two lights or a light and a tone.

When two $\mathbf{S}^{\mathbf{D}_{\mathbf{S}}}$ from the same sensory modality are presented simultaneously, there will be an increase in the physical intensity of the effective stimulus. A large body of literature, using both between- and within-groups designs, has demonstrated that as the intensity of a stimulus is increased, the level of response maintained by that stimulus is also increased (Gray, 1965; Grice, 1968; Pierrel, Sherman, Blue, and Hegge, 1970). In order to assess possible effects of stimulus intensity during compounding of lights, different subjects were trained with different combinations of visual stimuli of different intensity.

\section{EXPERIMENT I}

\section{METHOD}

\section{Subjects}

Eleven male albino rats were maintained at $80 \%$ of their free-feeding weights for the course of the experiment.

${ }^{1}$ This research was supported in part by a grant from the Bureau of Faculty Research, Western . Washington State College. Reprints may be obtained from the author, Department of Psychology, Western Washington State College, Bellingham, Washington 98225. 


\section{Apparatus}

A standard Grason-Stadler operant chamber was housed in a chest that shielded it from external stimuli and placed in a room separate from the scheduling equipment. Two fans provided ventilation and a masking noise. A force of $25 \mathrm{~g}(0.25 \mathrm{~N})$ was necessary to depress the response lever. The auditory stimulus was a $1475-\mathrm{Hz} 96-\mathrm{dB}$ tone (re. 0.0002 dynes $/ \mathrm{cm}^{2}$ ), $20 \mathrm{~dB}$ above the 76-dB ambient sound level in the chamber. A Jackson audio oscillator served as the tone source. Intensity of the tone was measured at the response lever with a General Radio Co. sound-level meter. The visual stimuli consisted of two G. E. houselight bulbs. The bulbs were attached to the outside righthand side of the clear plastic chamber door. The top bulb (L 1) was located $1 \mathrm{in} .(2.54 \mathrm{~cm})$ from the top of the door and the bottom light (L 2) the same distance from the bottom of the door. A distance of 6.25 in. $(16 \mathrm{~cm})$ separated the two bulbs. The intensity of each bulb was measured at the response lever and at an equal distance from each of the two houselights. For Subjects 9 to $11, \mathrm{~L} 1$ remained in the same position as for Subjects 1 to 8. L 2, however, was placed directly opposite and at the same height as $\mathrm{L} 1$ on the outside of the clear plastic left side wall. The sensing head of the light meter was placed equidistant from the two lights, 1 in. $(2.54 \mathrm{~cm})$ from the lever and directly facing it.

\section{Procedure}

The procedure used by Miller and Ackley (1970) was followed, because it allows for probe presentations of the compound during regular presentations of the single $\mathbf{S}^{\mathbf{D}_{\mathbf{S}}}$. This procedure contrasts with the extinction technique (e.g., Wolf, 1963), in which no reinforcement occurs during single and compound stimulus presentations.

Subjects were trained to bar press for $45-\mathrm{mg}$ Noyes pellets and were then given discrimination training. Responses were reinforced on fixed-interval (FI) schedules only in the presence of one of the three $S^{D_{s}}$, either L 1, L 2, or tone $(T)$. Absence of these stimuli signalled no reinforcement $\left(S^{\Delta}\right)$. A period of $S^{\Delta}$ intervened between successive FIs. The first response to occur at the end of a fixed interval was reinforced, terminated the $S^{D}$, and began the $S^{\Delta}$ period. Duration of $S^{\Delta}$ was randomly varied so that the subject could not use the food pellet as a cue to estimate the beginning of the next FI. The average duration of $\mathrm{S}^{\Delta}$ was $35 \mathrm{sec}$, with a range from 15 to $55 \mathrm{sec}$. Any response emitted during $S^{\Delta}$ stopped the tape puller, which timed the $S^{\Delta}$ interval, for $10 \mathrm{sec}$. Additional responses emitted during this 10 -sec period recycled the interval. Occurrence of either $\mathrm{L} 1, \mathrm{~L} 2$, or $\mathrm{T}$ during the FI was randomly determined, with the stipulation that each stimulus occur nearly equally often during each 2-hr session.

Responding was maintained on this schedule for 26 days, by which time discrimination between $S^{D}$ and $S^{\Delta}$ had developed. Responding was confined largely to presentations of the

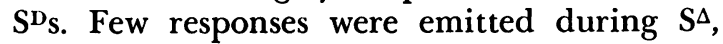
usually about 1 to $10 \%$ of the number of responses emitted during $S^{D}$ presentations. Stimulus compounding tests then commenced. In addition to presentation of the single $S^{D_{S}}$, each of the three possible compounds (L1 + L2, L1 $+\mathrm{T}, \mathrm{L} 2+\mathrm{T}$ ) was also presented during the FI when only one stimulus normally appeared. Order of presentation of the three compounds and the FI during which the compound appeared were both randomized. Compounding occurred on the average of every fourth to sixth FI. Responding during both single and compound stimulus presentations was reinforced.

Subjects 1 to 8 were naive. Subjects 9 to 11 had been used in the Miller and Ackley (1970) study. They had been trained with $\mathrm{T}$ and $\mathrm{L} 1$. For this experiment, the intensity of $\mathrm{L} 1$ was increased and $L 2$ was added. Tone remained the same. Responding by Subjects 1 to 8 was maintained by FI 90 -sec; Subject 9 , by FI 60 sec, and Subjects 10 and 11, by FI 120-sec. Subjects 1 to 8 and 10 and 11 received two presentations of each of the three compound stimulus combinations during each test session. Compounding was carried out over four days, yielding a total of eight presentations of each compound for each subject. Subject 9 , since it responded on a briefer FI schedule, and therefore received more presentations of the $S^{\mathbf{D}} \mathbf{s}$, was given three presentations of each compound for each of the four days of testing.

In order to examine the influence of stimulus intensity during compounding, subjects were trained under one of three different light intensity combinations. Tone remained constant. For Subjects 1 to 4, both lights were of equal and low intensity; $L 1=67.7 \mathrm{~cd} / \mathrm{m}^{2}$ 
$\left(19.9 \mathrm{ft}\right.$ candles) and $\mathrm{L} 2=61.2 \mathrm{~cd} / \mathrm{m}^{2}(18.0 \mathrm{ft}$ candles). Intensity of the $\mathrm{L} 1+\mathrm{L} 2$ compound was $129.2 \mathrm{~cd} / \mathrm{m}^{2}$ (38.0 ft candles). For Subjects 5 to $8, \mathrm{~L} 1$ was of moderate intensity (225.1 $\mathrm{cd} / \mathrm{m}^{2}$ or $66.2 \mathrm{ft}$ candles) and $\mathrm{L} 2$ was of low intensity $\left(83.3 \mathrm{~cd} / \mathrm{m}^{2}\right.$ or $24.5 \mathrm{ft}$ candles). Intensity of the compound was $306.7 \mathrm{~cd} / \mathrm{m}^{2}$ or 90.2 ft candles. For Subjects 9 to 11, L 1 was of high intensity (380.8 cd $/ \mathrm{m}^{2}$ or $112.0 \mathrm{ft}$ candles) and $\mathrm{L} 2$ was of moderate intensity $\left(225.1 \mathrm{~cd} / \mathrm{m}^{2}\right.$ or $66.2 \mathrm{ft}$ candles). $\mathrm{L} 1$ and $\mathrm{L} 2$ combined had an intensity of $604.2 \mathrm{~cd} / \mathrm{m}^{2}$ or $177.7 \mathrm{ft}$ candles. It should be noted that the light bulbs for the low-intensity lights for Subjects 1 to 4 and 5 to 8 were identical. The slight differences in intensity were most probably due to slight variations in the placement of the sensing head of the light meter when measurements were taken.

\section{Results AND Discussion}

The mean number of responses emitted during the single and compound $S^{D}$ presentations for all of the test days for each subject in each intensity group is presented in Table 1 . In all instances each of the three compounds maintained a higher frequency of response than either of its component $\mathrm{S}^{\mathbf{1}} \mathbf{s}$. This difference was statistically reliable at the 0.005 level of significance with each of the three intensity groups, using the Walsh test (Siegel, 1956, p. 83).

Next, level of responding maintained by inter- and intra-modal compounds was examined. The two compounds were compared in terms of what per cent compound responding was of the sum of the response frequencies of

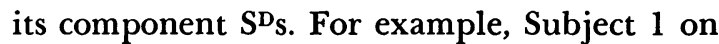
Test Day 1 emitted a mean of 14.7 and 8.6 responses to $L 1$ and $L 2$, respectively, which totals 23.3 responses to the two stimuli added together. Nineteen responses were emitted to the compound of $\mathrm{L} 1+\mathrm{L} \mathrm{2}$, which is $81 \%$ of 23.3. The use of a ratio between single and compound response frequencies permits a more direct comparison between compounds than would comparing number of responses, since absolute number of emitted responses might be different for each compound. Of course, this percentage is not independent of frequency of response to the component $S^{D_{S}}$. As this frequency becomes larger and larger and approaches a limit, the percentage by which the compound can exceed the sum of the single stimuli must necessarily diminish. However, in the present study, it appears that this may have happened only with Subject 7 . It should also be noted that the compounds are compared on the basis of a simple additive combination rule, since this rule fitted the average rate to compound stimuli across different light intensities, light locations, and FI schedule values; also see Miller and Ackley (1970). Any other reasonable rule could just as well have been used.

A mean percentage, ignoring the intensity of the lights and based on all 11 subjects' scores, was computed for each of the four test days and the four days combined. The results are presented in panel A of Fig. 1. In panels B and $C$, responding is separated in terms of light intensity. Panel B, based on the scores for the four test days, compares the Light +

Table 1

Mean number of responses emitted by each subject during single and compound stimulus presentations for the four days of testing.

\begin{tabular}{|c|c|c|c|c|c|c|}
\hline Subject & Light 1 & Light 2 & Tone & Light $1+$ Light 2 & Light $1+$ Tone & Light $2+$ Tone \\
\hline 1 & 12.9 & 14.4 & 12.4 & 23.2 & 33.5 & 29.2 \\
\hline 2 & 27.0 & 15.4 & 10.4 & 35.4 & 44.7 & 48.9 \\
\hline 3 & 22.2 & 21.1 & 19.4 & 26.2 & 31.2 & 27.3 \\
\hline 4 & 11.7 & 10.2 & 17.9 & 32.6 & 43.7 & 57.1 \\
\hline $1-4$ & 18.5 & 15.3 & 15.0 & 29.4 & 38.3 & 40.6 \\
\hline 5 & 8.0 & 6.9 & 9.3 & 9.2 & 12.0 & 9.4 \\
\hline 6 & 17.3 & 19.3 & 18.8 & 24.9 & 31.7 & 33.6 \\
\hline 7 & 52.0 & 63.7 & 60.0 & 82.4 & 83.8 & 96.6 \\
\hline 8 & 22.0 & 21.6 & 28.3 & 44.9 & 37.4 & 40.6 \\
\hline $5-8$ & 24.8 & 27.9 & 29.1 & 40.3 & 41.2 & 44.8 \\
\hline 9 & 11.8 & 9.5 & 7.6 & 16.9 & 23.6 & 18.0 \\
\hline 10 & 15.5 & 9.7 & 13.2 & 26.4 & 27.2 & 27.8 \\
\hline 11 & 12.0 & 14.1 & 14.8 & 25.9 & 26.9 & 35.6 \\
\hline $9-11$ & 13.1 & 11.1 & 11.9 & 23.1 & 25.9 & 27.1 \\
\hline
\end{tabular}




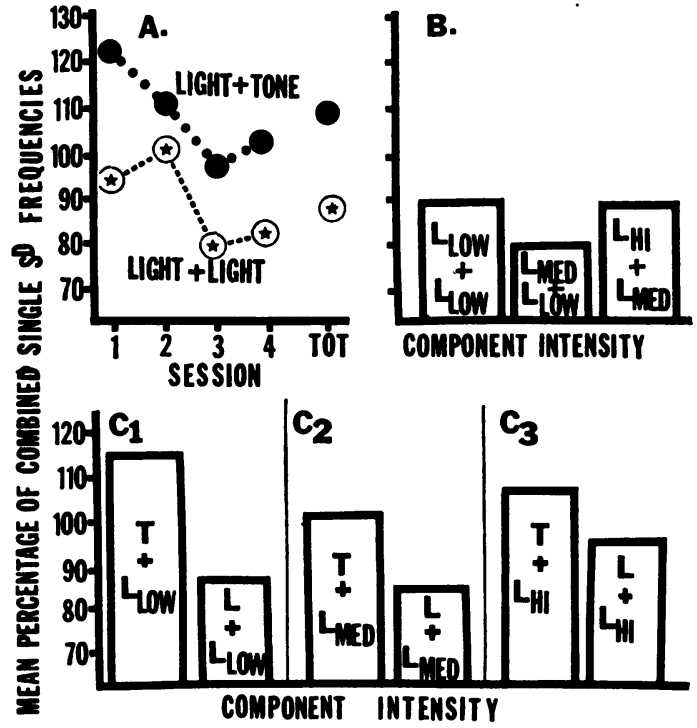

Fig. 1. Compound responding's percentage of the sum of the response frequencies of its component $S^{\mathrm{n}} \mathrm{s}$. Panel A presents the comparison between compounds for all subjects for each and for all of the four test sessions. Panel B presents the comparison for the Light + Light compounds for each of the three intensity groups. In panel C, the Tone + Light compounds are compared to the Light + Light compounds when one of the lights was of the same intensity for both of the compounds.

Light compound for each of the three intensity groups (Subjects 1 to $4 ; 5$ to $8 ; 9$ to 11 ). Panel $\mathrm{C}$, based on the scores for the four test days, compares responding to the two compounds when one of the lights was of the same intensity for both compounds. In panel $C_{1}$, the light was of low intensity; these data were contributed by Subjects 1 to 4 ( $\mathrm{L} 1+\mathrm{T}$ and $\mathrm{L} 2$ $+\mathrm{T} ; \mathrm{L} 1+\mathrm{L} \mathrm{2}$ ) and Subjects 5 to 8 (L 2+ T; $\mathrm{L} 1+\mathrm{L} 2$ ). In panel $\mathrm{C}_{2}$, the light was of moderate intensity; these data were contributed by Subjects 5 to 8 (L 1 + T; L 1 + L 2) and Subjects 9 to $11(\mathrm{~L} 2+\mathrm{T} ; \mathrm{L} 1+\mathrm{L} 2)$. In panel $\mathrm{C}_{3}$, the light was of high intensity; these data were contributed by Subjects 9 to 11 (L $1+\mathrm{T}$; L 1 + L 2).

The results presented in Table 1 confirm the finding, using a within-subjects design, that a compound composed of $S^{D_{S}}$ from the same or different sensory modalities will maintain a greater frequency of response than that maintained by either of its component $\mathbf{S}^{\mathbf{D}_{\mathbf{S}} \text {. }}$

The results illustrated in Fig. 1, panels $A$ and $C$, indicate that the sensory modalities of the $S^{D_{S}}$ can affect level of responding maintained by the compound. In each instance the inter-modal compound maintained a higher percentage of the combined component $\mathrm{S}^{\mathrm{D}}$ frequencies than did the intra-modal compound. It is also worth nothing that analysis of Wolf's (1963, Fig. 1, p. 345) results yields the same conclusion with a between-subjects design. The rat that Wolf trained with a light and toned emitted a greater number of responses during compounding than rats trained with lights, when the number of responses emitted during the component $\mathrm{SD}^{\mathbf{D}}$ was about the same.

Why the two compounds should maintain different levels of responding is not readily apparent. Suggestive evidence may come from the phenomenon of sensory interaction. It is well-established that simultaneous presentation of a stimulus from one sense modality can facilitate the response correlated with a stimulus from another modality (e.g., Zajonc and Dorfman, 1964). Bernstein, Clark, and Edelstein (1969) hypothesized that the faster reaction time to a visual stimulus when presented with a tone than when presented alone might be due to summation of the two energy sources. Presumably, this summation of energy sources would not occur when both stimuli were from the same sensory modality.

No consistent or predictable effects of light intensity were noted. It would be predicted that as intensity of the component $S^{D_{s}}$, and, therefore, compound $S^{D}$, increased, level of responding maintained by the compound relative to level of responding maintained by the component stimuli should also increase. However, the results presented in panels $B$ and $C$ of Fig. 1 do not verify this expectation. In panel $B$, the percentages for the $L_{\text {Low }}+L_{\text {Low }}$ and $\mathrm{L}_{\mathrm{HI}}+\mathrm{L}_{\mathrm{MED}}$ compounds were nearly equal even though the light intensities correlated with each compound were markedly different; and the percentage for the intermediate $L_{M E D}$ $+\mathrm{L}_{\text {Low }}$ compound was below the percentage for the other two compounds. In panel $\mathrm{C}$, the $\mathrm{L}+\mathrm{L}_{\mathrm{HI}}$ compound did maintain a higher percentage than was maintained by the other two less-intense compounds. However, the percentages for these other two compounds were about equal, even though the intensities were quite different.

Weiss (1969) and Meltzer and Freeman (1971) also reported a lack of intensity effects during compounding under circumstances opposite from those of the present study. Weiss, for example, made the compound less intense 
than either single $S^{D}$ by having light-silence and tone-darkness as his component $S^{D^{D}}$. The compounds of darkness and silence produced more responses than did either light or tone separately.

One possibly important factor accounting for the successful demonstration of intensity effects in standard stimulus intensity studies and the failure to demonstrate intensity effects during stimulus compounding is that, in the former situation, changes in intensity are effected through a single stimulus. With stimulus compounding, however, this change is effected by simultaneously presenting two stimuli from the same sensory modality. If typical intensity effects are demonstrable only when effected through a single stimulus, then increasing the intensity of the component $S^{D_{S}}$ should increase frequency of responding. A compound composed of $\mathbf{S}_{\mathbf{S}}$ that are each more intense than the $\mathrm{S}^{\mathrm{D}} \mathrm{S}$ of another compound should maintain a higher frequency of response. Experiment 2 tested the validity of this assumption.

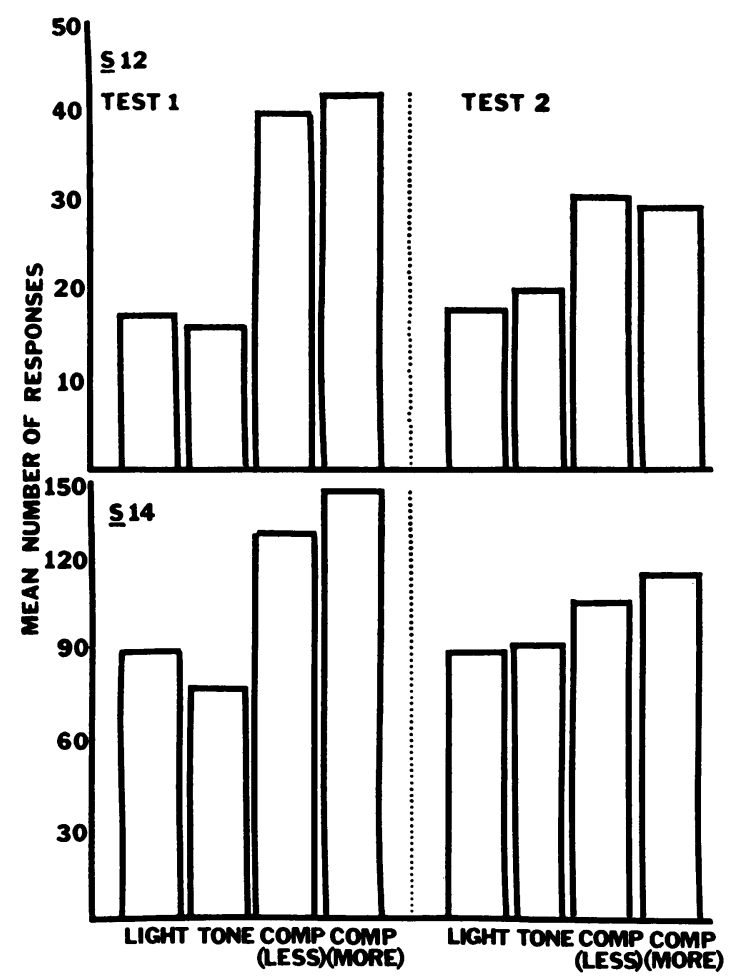

\section{EXPERIMENT 2}

Four different rats (Subjects 12 to 15) were trained and tested with the same procedure followed in the first experiment. Responding was maintained by FI 90 -sec schedules. L 1 served as one $S^{D}$ and was of $30.6 \mathrm{~cd} / \mathrm{m}^{2}(9.0 \mathrm{ft}$ candles) intensity. Tone served as the other $\mathrm{S}^{\mathrm{D}}$ and had an intensity of $88 \mathrm{~dB}, 12 \mathrm{~dB}$ above the ambient noise level. During compound testing, two intensities of light and tone compound were presented to each subject. One compound consisted of the light and tone intensities used during training. Intensity of each of the $S^{D_{S}}$ in the second compound was approximately twice the intensity of each $S^{D}$ of the first compound. The light's intensity was increased by $30.6 \mathrm{~cd} / \mathrm{m}^{2}$ to $61.2 \mathrm{~cd} / \mathrm{m}^{2}(18.0 \mathrm{ft}$ candles) and the tone's intensity was increased by $10 \mathrm{~dB}$ to $98 \mathrm{~dB}, 22 \mathrm{~dB}$ above the ambient noise level. Intensity of the single stimuli never changed. Intensity changes were made with a rheostat during the $S^{\Delta}$ period between each FI. Each compound intensity was presented three times

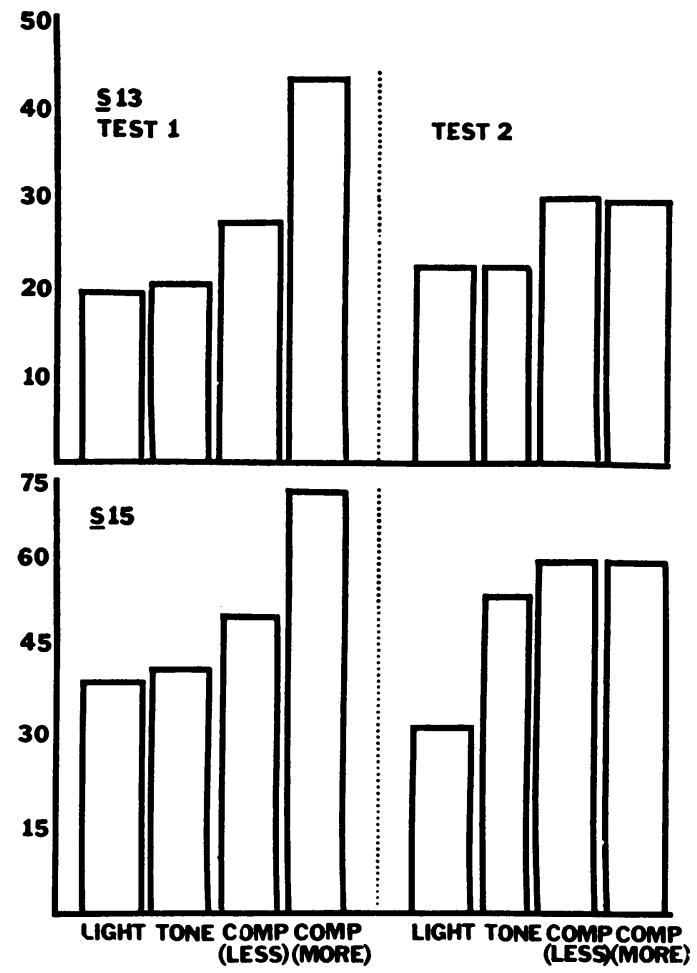

Fig. 2. Mean number of responses emitted by each subject during single and compound stimulus presentations for each of the two days of testing. The less and more intense compounds are denoted by, respectively, COMP (LESS) and COMP (MORE). 
during a session, in alternating order. Subjects were tested for two sessions.

\section{Results ANd Discussion}

The mean number of responses emitted during component stimulus presentations and during each compound stimulus intensity for each session are presented in Fig. 2. Both compounds maintained a higher frequency of response than did either single stimulus, and for the first test session the more-intense compound maintained a higher frequency of response than did the less-intense compound. This intensity effect was generally transitory, however, even though intensity of both light and tone were substantially increased and a within-subjects design, which produces maximum intensity effects (Grice, 1968), was used. There was essentially no difference in responding maintained by the two compounds during the second test session. Only with Subject 14 was there a noticeably higher frequency of response during the more-intense compound for Session 2, but even this difference was attenuated by the second test session. These results demonstrate that stimulus intensity can affect level of response maintained by a compound stimulus, albeit temporarily, when the intensity changes are effected through the component $\mathbf{S}^{\mathbf{D}_{\mathbf{S}} \text {. }}$

These data also suggest that intensity effects may have been present in Exp. 1 during the first session of intra-modal compounding, but were obscured because the data from all four test sessions was pooled. However, analysis of Session 1 data only from Fig. 1, panels B and $\mathrm{C}$ revealed no such effect. The highest percentage was correlated with the lowest intensity compound, and the middle intensity compound was correlated with the lowest percentage.

In conclusion, several variables will affect level of responding to a compound stimulus, for example, schedule of reinforcement (Weiss, 1964; Weiss, 1967) and level of responding maintained by the $\mathbf{S D}^{\mathbf{D}_{\mathrm{S}}}$ (Miller and Ackley, 1970). To this list can be added the variables of sensory modalities of the $S^{D}$, and, at least initially, intensity of the $S^{D}$.

\section{REFERENCES}

Bernstein, I. H., Clark, M. H., and Edelstein, B. A. Intermodal effects in choice reaction time. Journal of Experimental Psychology, 1969, 81, 405-407.

Gray, J. A. Stimulus intensity dynamism. Psychological Bulletin, 1965, 3, 180-196.

Grice, G. R. Stimulus intensity and response evocation. Psychological Review, 1968, 75, 359-373.

Grings, W. M. and O'Donnell, D. E. Magnitude of response to compounds of discriminated stimuli. Jour nal of Experimental Psychology, 1956, 52, 354-359.

Hull, C. L. Explorations in patterning of stimuli conditioned to the G.S.R. Journal of Experimental Psy. chology, 1940, 27, 95-110.

Kimble, G. A. Hilgard and Marquis' conditioning and learning. New York: Appleton-Century-Crofts, 1961.

Meltzer, D. and Freeman, Betty J. Maintenance of response summation under conditions of minimum stimulus intensity. Psychonomic Science, 1971, 22, 287-289.

Miller, L. and Ackley, R. Summation of responding maintained by fixed-interval schedules. Journal of the Experimental Analysis of Behavior, 1970, 13, 199-203.

Miller, L. and Price, R. D. Stimulus compounding and response summation with an instrumental running response. Psychonomic Science, 1971, 22, 52-53.

Pierrel, Rosemary; Sherman, J. G., Blue, S., and Hegge, F. W. Auditory discrimination: a three-variable analysis of intensity effects. Journal of the Experimental Analysis of Behavior, 1970, 13, 17-35.

Siegel, S. Nonparametric statistics. New York: McGraw-Hill, 1956.

Weiss, S. J. Summation of response strengths instrumentally conditioned to stimuli in different sensory modalities. Journal of Experimental Psychology, 1964, 68, 151-155.

Weiss, S. J. Free-operant compounding of variable-interval and low-rate discriminative stimuli. Journal of the Experimental Analysis of Behavior, 1967, 10, 535-540.

Weiss, S. J. Attentional processes along a composite stimulus continuum during free-operant summation. Journal of Experimental Psychology, 1969, 82, 22-27.

Wolf, M. M. Some effects of combined $\mathbf{S}^{\mathbf{D}} \mathbf{s}$. Journal of the Experimental Analysis of Behavior, 1963, 6, 343-347.

Zajonc, R. B. and Dorfman, D. D. Perception, drive, and behavior theory. Psychological Review, 1964, 71, 273-290.

Received: 6 August 1970.

(Final Acceptance: 23 June 1971.) 